\title{
Effect of fribrinigen degradation products on various stages of the fibrinolytic process
}

\author{
Tetiana Yatsenko', Valentina N. Rybachuk', Svetlana M. Kharchenko', Tetiana V. Grinenko', \\ Elena I. Yusova' \\ 1 Palladin Institute of Biochemistry of NAS of Ukraine
}

Yatsenko T, Rybachuk VN, Kharchenko SM, Grinenko TV, Yusova El. Effect of fribrinigen degradation products on various stages of the fibrinolytic proces. J Pre-Clin Clin Res. 2015; 9(1): 18-22. doi: 10.5604/18982395.1157570

\begin{abstract}
Over-activation of the fibrinolytic system may result in proteolytic destruction of fibrinogen. However, the effect of the degradation products formed during fibrinogenolysis on fibrinolytic process and plasminogen/plasmin properties remains unclear. To investigate this effect and its mechanism, the ability of fibrinogen fragments $E$ and $D$ to act on plasminogen and tPA binding, proenzyme activation, fibrin clot lysis and plasmin inhibition by plasma a2-antiplasmin, were studied. It was found that early product fragment $\mathrm{E}_{\mathrm{E}}$ binds to plasminogen and tissue-type plasminogen activator and enhances plasminogen conversion into plasmin. C-terminal lysine residues of all 3 chains pair and 16 or 23 amino acid residues of Aachain are essential for this process. C-terminal lysines of fragment $E$ Aa- and $\gamma$-chains and lysine-binding site of tPA kringle 2 are responsible for the interaction between these proteins. Binding of fragment $\mathrm{E}$ to plasminogen is provided by $\mathrm{N}$-terminal Aa1-19 and C-terminal B $\beta 120-122$ regions. Late plasmic fibrinogen degradation product fragment $E_{L}$ loses the ability to potentiate plasmin generation but can bind proenzyme and its activator. Fragment $D$ has no binding properties towards plasminogen and tPA. None of fibrinogen fragments protects plasmin from a2-antiplasmin inhibition. It is concluded that at over-activation of the fibrinolytic system and subsequent fibrinogenolysis, the products of fibrinogen degradation, can bind plasminogen and tPA and potentiate generation of plasmin, which will be neutralized under the normal level of the plasmin inhibitor.
\end{abstract}

\section{Key words}

fibrinolysis, plasminogen, tissue-type plasminogen activator, fibrinogen degradation products

\section{INTRODUCTION}

Fibrinolytic system activation is an appropriate response to blood clotting and mainly serves for the lysis of polymeric fibrin depositon. The main fibrinolytic enzyme plasmin is generated from inert precursor plasminogen by either tissue-type plasminogen activator (tPA) or urokinase-type plasminogen activator (uPA). Plasminogen and tPA from plasma bind to specific sites in fibrin during fibrinogen conversion to fibrin, and plasminogen activator cleaves proenzyme into plasmin [1]. Plasmin then destructs fibrin into soluble fibrin degradation products (noncovalent DDE complex, cross-linked dimeric fragment D-D and fragment E) that release into the bloodstream. The remaining enzyme, after clot dissolution, is inactivated by plasma inhibitors (mainly by a2-antiplasmin) [2].

Under pathophysiological conditions, over-activation of the fibrinolytic system can cause proteolytic destruction of fibrinogen, and severe bleeding may occur. Fibrinogenolysis may complicate various disorders, such as disseminated intravascular coagulopathy, severe liver disease, tumour, vascular surgery, inflammation, and an inherited or acquired defective fibrinolytic mechanism [3, 4]. Common adverse effects of all the thrombolytic drugs are the bleeding complications related to systemic fibrinogenolysis and lysis of normal hemostatic plugs. Fibrinogen destruction results in fragments $\mathrm{D}$ and $\mathrm{E}$ formation that is consequence of plasmin

Address for correspondence: Tetiana Yatsenko, Palladin Institute of Biochemistry of NAS of Ukraine, 9 Leontovicha St., 01601, Kyiv, Ukraine

E-mail: topolius@yandex.ua

Received: 25 March 2015; accepted: 22 May 2015 generation within the general blood circulation and exceeded neutralizing ability of plasma inhibitors of fibrinolysis [4].

Fibrinogen/fibrin degradation products (FDPs) are the markers for the fibrinolysis activation level. FDPs concentration in blood becomes increased under the thrombotic disorder, surgery complications, etc. FDPs participate in a range biological process, such as platelet activation, adhesion and aggregation, vessel wall permeability, fibrinogen synthesis, and blood cell function. Fibrin fragments are characterized by the binding affinity to the t-PA and plasminogen, effect on fibrin polymerization and activation process $[5,6]$. Fragment D and D-dimer inhibit fibrin polymerization. However, the effect of degradation products formed during fibrinogenolysis on the fibrinolytic process and plasminogen/ plasmin properties, remains unclear. The presented study addresses these issues.

To investigate this effect and its mechanism, the ability of fibrinogen fragments $\mathrm{E}$ and $\mathrm{D}$ to act on various stages of the fibrinolytic process, namely, on plasminogen and tPA binding, proenzyme activation, fibrin clot lysis and plasmin inhibition by plasma a2-antiplasmin, was studied. To determine the structures of the fragment $\mathrm{E}$ molecule responsible for the interactions with fibrinolytic system components, early and late fibrinogen degradation products and fragments $E$ treated by carboxypeptidase B and thrombin were used.

\section{MATERIALS AND METHODS}

Fibrinogen was purified from human plasma by fractionation with sodium sulfate [7]. Glu-plasminogen was prepared from citrate donor plasma using the Lysine-sepharose affinity 
chromatography [8]. Plasmin was obtained by activation of Glu-plasminogen with urokinase, immobilized to Sepharose 4B [8]. The recombinant single-chain tPA was a Boehringer Ingelheim product known under the trade name "Actylise".

Fibrinogen degradation products were prepared from plasmin digest of human fibrinogen. Digestion was performed at $37^{\circ} \mathrm{C}$ in $0.05 \mathrm{M}$ TBS with $0.15 \mathrm{M} \mathrm{NaCl}(\mathrm{pH}$ 7.4 ), concentration of fibrinogen was $10 \mathrm{mg} / \mathrm{ml}$, plasmin - $0.2 \mathrm{CU} / \mathrm{ml}$, calcium ion - $5 \mathrm{mM}$. Early and late plasmic degradation products were obtained after 1 and 6 hours of hydrolysis, respectively. Reaction was inhibited by $1,000 \mathrm{KIU}$ aprotinin (Merckle $\mathrm{GmbH}$ ) per $1 \mathrm{ml}$ of reactive solution. Early $\left(E_{\mathrm{E}}\right)$ and late $\left(\mathrm{E}_{\mathrm{L}}\right)$ fragments $\mathrm{E}$ and fragment $\mathrm{D}$ were purified by ion-exchange chromatography on CM-Sephadex G-50, as described elsewhere [9].

Early fragment $\mathrm{E}$ without C-terminal lysines $\left(\mathrm{E}_{\mathrm{CPB}}\right)$ was prepared by carboxypeptidase B (Sigma) treatment (final molar ratio to fragment - 1/50) for $30 \mathrm{~min}$ at room temperature in $0.1 \mathrm{M}$ TBS ( $\mathrm{pH} 8.1$ ).

Early fragment $\mathrm{E}$ without fibrinopeptide $\mathrm{A}\left(\mathrm{E}_{\mathrm{Thr}}\right)$ was prepared by thrombin (Sigma) treatment (3.3 NIH units of thrombin per $1 \mathrm{mg}$ fragment) for $30 \mathrm{~min}$. Thrombin was removed by Heparin-Sepharose $6 \mathrm{~B}$.

Monomeric desAB-fibrin was obtained by dissolving a thrombin fibrin clot formed in the presence of $50 \mathrm{mM}$ $\varepsilon$-aminocaproic acid ( $\varepsilon$-ACA) and parahydroxy mercury benzoate $(0.35 \mathrm{mg} / \mathrm{ml})$ in $20 \mathrm{mM}$ acetic acid, as described elsewhere [10].

All proteins were tested for homogeneity by $8-12 \%$ SDS-PAGE. Protein concentrations were calculated by measurement of the absorbance at 280 and $320 \mathrm{~nm}$ using $\mathrm{E}_{1 \%}^{280}$ and molecular weights respectively: Glu-plasminogen, 17.0 and 92 000; plasmin, 17.0 and 84 000; tPA, 20.0 and 59 000; fibrinogen, 15.5 and 340 000; fragment D, 20.0 and 95 000; fragment $\mathrm{E}_{\mathrm{E}}, 10.0$ and 60000 ; fragment $\mathrm{E}_{\mathrm{L}} 10.0$ and 45000 .

The stimulating effect of fibrinogen fragments on the tPA-catalyzed conversion of plasminogen into plasmin was evaluated by determination of the amidolytic activity of the newly-formed plasmin with chromogenic substrate S-2251 (H-D-valyl-L-leucyl-L-lysine-p-nitroanilide). The assay system contained $0.22 \mu \mathrm{M}$ Glu-plasminogen, $0.09 \mathrm{nM}$ tPA, $0.3 \mathrm{mM} \mathrm{S}-2251$, and $0.625 \mu \mathrm{M}$ monomeric desAB-fibrin and/or $0.22 \mu \mathrm{M}$ fibrinogen fragments in $0.05 \mathrm{M}$ TBS with $0.15 \mathrm{M} \mathrm{NaCl}$ ( $\mathrm{pH} 7.4$ ) containing $0.05 \%$ Tween 80 . The assay was performed in a microtiter 96 -well plate at $37^{\circ} \mathrm{C}$. The amidolytic activity was determined by measurement of the absorbance at $405 \mathrm{~nm}$ using Titertek Multiscan MC 96-well plate reader (Berthold Detection Systems).

Isomolar series were carried out using chromogenic substrate assay, as described above. The total number of Gluplasminogen and fragment $\mathrm{E}$ molecules in each series was the same. Molar ratio plasminogen/fragment was from $9 / 1$ $-1 / 9$. Maximum concentration of each protein was $0.39 \mu \mathrm{M}$.

Binding assay was performed using the avidin-biotin system (Thermo Scientific). Biotin labeling of Glu-plasminogen and tPA was carried out according to the manufacturer's recommendation. The wells of high binding polysterene microtitrate plates (Nunc MaxiSorp) were coated with $1 \mu \mathrm{g}$ fragments in $0.1 \mathrm{ml} 0.01 \mathrm{M}$ sodium phosphate buffer ( $\mathrm{pH} 7.4$ ) and $0.15 \mathrm{M} \mathrm{NaCl}$ at $4{ }^{\circ} \mathrm{C}$ overnight. After binding, the excess fragments were removed by washing buffer with $0.1 \%$ Tween 80 . To avoid nonspecific sorption, $2 \%$ BSA was pippeted into the plate wells, incubated for 2 hours at $37^{\circ} \mathrm{C}$ and washed out. After washing procedures, binding fragments in each well were incubated with $0.1 \mathrm{ml}$ biotinylated plasminogen or tPA for 4 hours at $37^{\circ} \mathrm{C}$ and washed out. Then, $0.1 \mathrm{ml}$ avidinphosphatase (soluted as manufacturer's recommendation) was added into the wells and washed out after $60 \mathrm{~min}$ incubation. $0.1 \mathrm{ml}$ alkaline phosphatase substrate $(1 \mathrm{mg} / \mathrm{ml}$ p-nitrophenyl phosphate in 10\% diethanolamine, $\mathrm{pH} 9.8$ ) was pippeted into the wells and incubated for 2 hour at $37^{\circ} \mathrm{C}$. Binding of biotin labeled proteins with fragments immobilized on well surface was estimated by measurement of p-nitrophenol absorbance at $405 \mathrm{~nm}$, using a Titertek Multiscan reader.

For the estimation of fibrinolytic activity of plasmin, the turbidimetric method was applied, as described in [11]. The final concentration of desAB-fibrin was $0.6 \mu \mathrm{M}$, plasmin $0.02 \mu \mathrm{M}$. The rate of fibrin clot lysis by plasmin was calculated as $\mathrm{V}=1 / \mathrm{t}_{50 \%}$. Time of $50 \%$ lysis $\left(\mathrm{t}_{50 \%}\right)$ was measured as the time period from the initiation step of the clot formation untill the step characterized by $50 \%$ fall in absorbance from maximum.

The blood plasma a2-antiplasmin effect was evaluated by inhibition of plasmin fibrinolytic activity. The blood plasma containing $0.06 \mathrm{mg} / \mathrm{ml}$ of inhibitor was added into the reaction mixture. Final molar ratio of a2-antiplasmin (MW 62000$)$ to enzyme was $1 / 1(0.02 \mu \mathrm{M})$. The rate of fibrin lysis by plasmin without plasma addition was taken as $100 \%$.

\section{RESULTS}

To investigate the ability of fibrinogen degradation products to affect the fibrinolytic system function, the effect of fragments $\mathrm{E}$ and $\mathrm{D}$ on Glu-plasminogen activation by rtPA on desAB-fibrin was assessed (Fig. 1). Each fragment was added into reaction medium in equimolar amounts to Gluplasminogen. It was found that neither fragment E nor fragment $D$ changed potentiation of plasmin generation by polymeric desAB-fibrin. However, it has been demonstrated that fragment $E_{E}$, but not fragments $E_{L}$ and $D$, potentiate plasminogen activation by tPA (Fig. 2). The rate of $\mathrm{E}_{\mathrm{E}}$ effect was approximately $30 \%$ of desAB-fibrin potentiation.

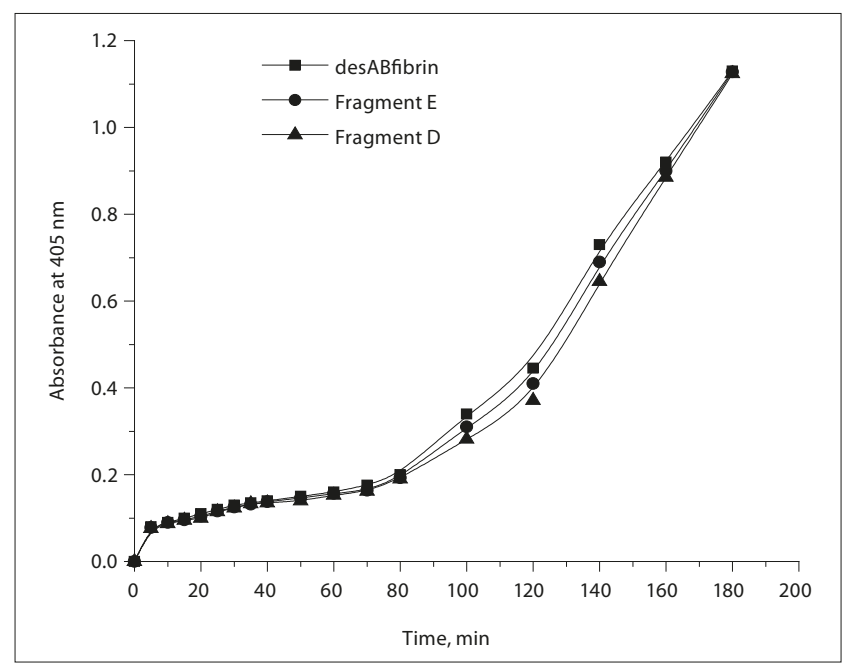

Figure 1. tPA-catalysed Glu-plasminogen activation on desAB-fibrin in fibrinogen fragments presence. Activation was measured by amidolytic activity assay. Absorbance of newly-formed $\mathrm{p}$-nitroanylin from $\mathrm{S}_{2251}$ indicates the rate of the plasmin formation from its precursor. Presence of fragments $D$ and $E$ (equimolar to plasminogen) does not change the kinetics of activation process 


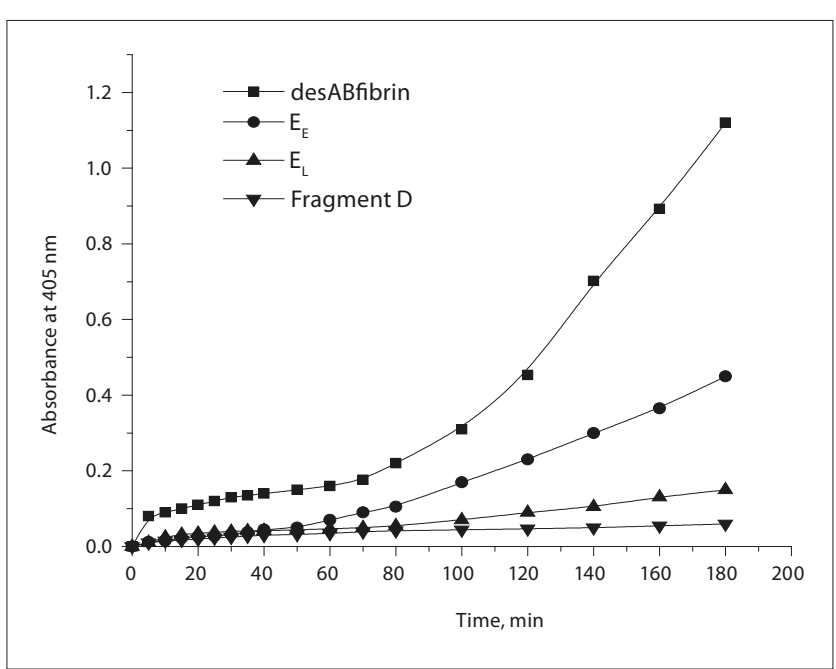

Figure 2. Potentiating effect of fibrinogen fragments on plasminogen activation by tPA. The level of desAB-fibrin-mediated stimulation of plasmin generation was taken as control in the amidolytic activity assay

By applying the method of izomolar-series, the maximum potentiating effect of fragment $\mathrm{E}_{\mathrm{E}}$ on tPA-catalysed plasminogen activation was established (Fig. 3). The effect was observed at a molar ratio of plasminogen to fragment $\mathrm{E}_{\mathrm{E}} 4 / 1$.

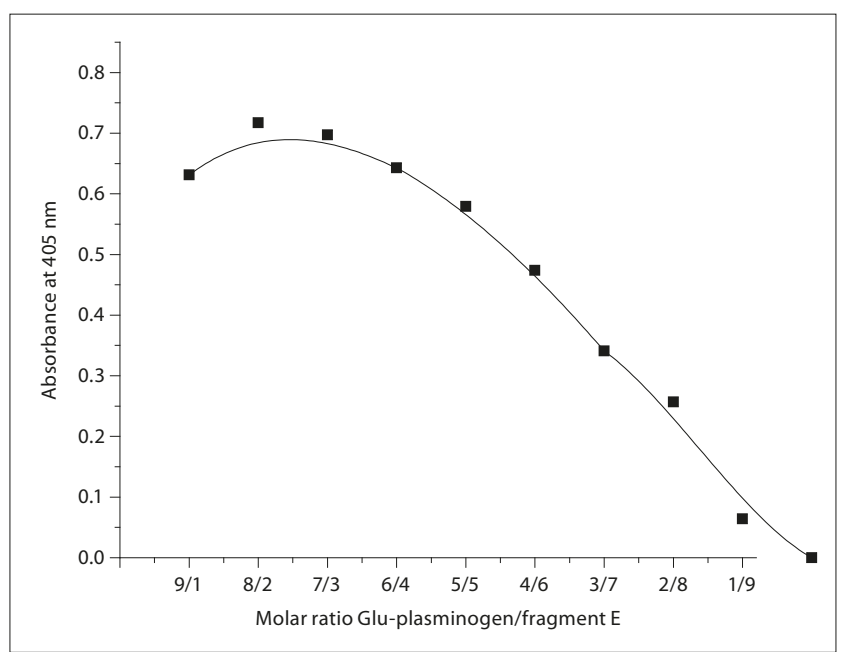

Figure 3. Isomolar series for fragment $\mathrm{E}_{\mathrm{E}}$-mediated plasminogen activation by tPA. Concentration of fragment $E_{E}$ and plasminogen was in range $0.043-0.39 \mu \mathrm{M}$. Maximum potentiating effect of fragment $E_{E}$ on plasminogen activation by tPA was observed at plasminogen and fragment concentrations 0.34 and $0.09 \mu \mathrm{M}$, respectively

To determine the significance of some parts of the fragment $\mathrm{E}$ molecule for interaction with fibrinolytic system components, the tPA and Glu-plasminogen binding to fragments $\mathrm{E}_{\mathrm{E}}, \mathrm{E}_{\mathrm{L}}$ and $\mathrm{E}_{\mathrm{CPB}}$ was investigated by using the avidin-biotin system (Fig. 4). It was shown that tPA affinity to $\mathrm{E}_{\mathrm{E}}$ and $\mathrm{E}_{\mathrm{L}}$ was the same, whereas carboxy-terminal lysines elimination resulted in a 9 -fold decrease of the activator binding. Furthermore, tPA binding to fragment $\mathrm{E}$ decreased in the presence of $\varepsilon$-ACA, which in $0.1 \mathrm{M}$ concentration almost suppressed interaction between fragment and lysinebinding sites of the activator (Fig. 5).

The results obtained on Glu-plasminogen binding to fragments $\mathrm{E}_{\mathrm{E}}, \mathrm{E}_{\mathrm{L}}$ and $\mathrm{E}_{\mathrm{CPB}}$ are shown in Fig. 6. Gluplasminogen was bound to early degradation product $\mathrm{E}_{\mathrm{E}}$ in higher quantities and with a higher affinity then to late

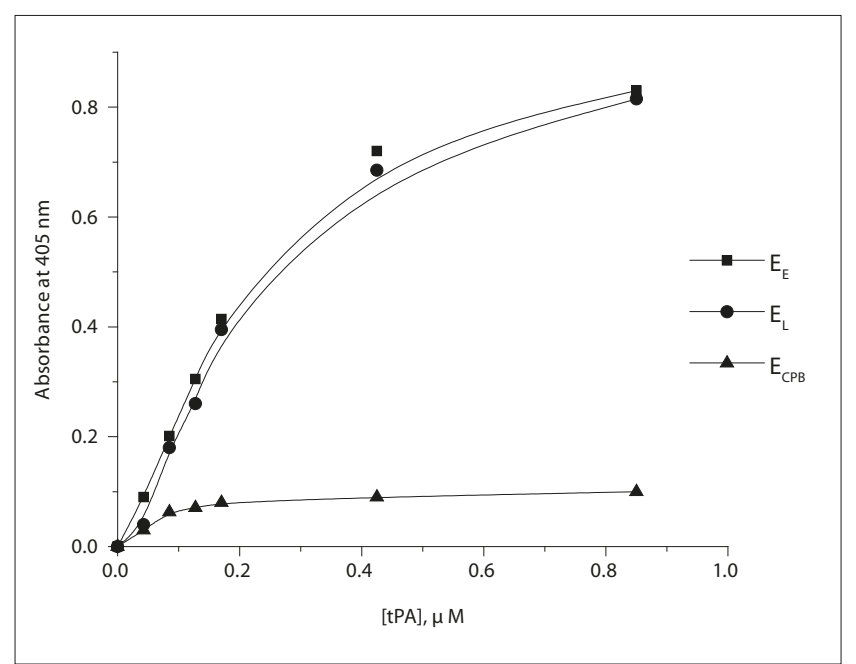

Figure 4. tPA binding to various fibrinogen fragments E. Binding ability of immobilized fragments was measured applying avidin-biotin system at range of biotin labeled tPA concentration $0.04-0.85 \mu \mathrm{M}$

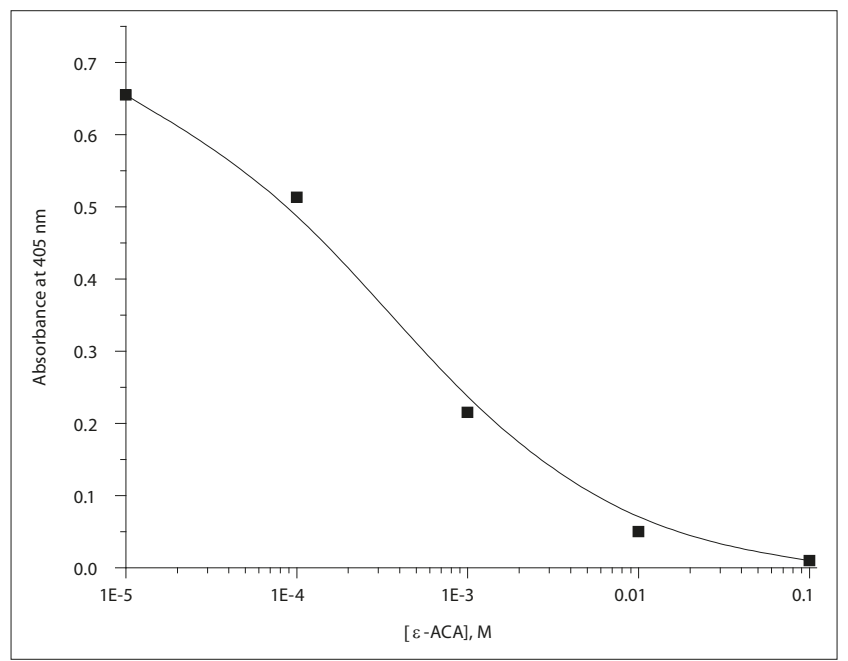

Figure 5. tPA binding to fragment $E_{E}$ in the presence of $\varepsilon$-ACA. Lysine analog $\varepsilon$-ACA (10-100 $000 \mu \mathrm{M})$ and biotin labeled activator $(0.85 \mu \mathrm{M})$ were co-incubated with immobilized fragment $E_{E}$. $\varepsilon$-ACA decreased tPA-binding ability of $E_{E}$ in dosedependent manner

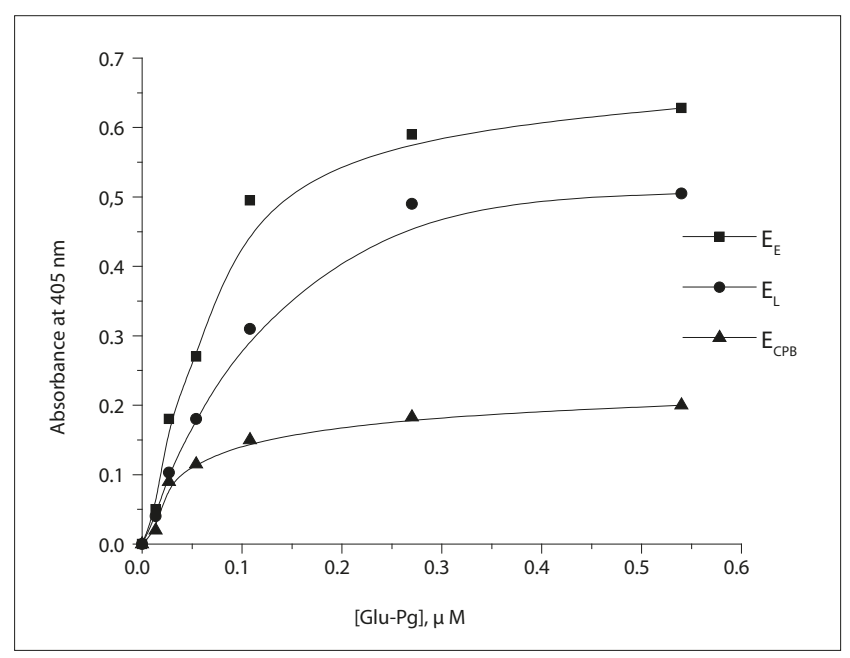

Figure 6. Glu-plasminogen binding to various fibrinogen fragments E. Concentration of biotin labeled plasminogen was from 0.01 to $0.54 \mu \mathrm{M}$ 
product $\mathrm{E}_{\mathrm{L}}$. Treatment of $\mathrm{E}_{\mathrm{F}}$ by carboxypeptidase $\mathrm{B}$ declined plasminogen binding only 3 -fold, while tPA binding decreased more intensely.

Chromogenic substrate assay of plasmin generation demonstrated that removing 16 amino-terminal amino-acid residues from $\mathrm{A} \alpha$-chain of $\mathrm{E}_{\mathrm{E}}$ by thrombin resulted in a $25 \%$ reduction of the plasminogen activation rate (Fig. 7). On the other hand, treatment of $\mathrm{E}_{\mathrm{E}}$ by carboxypeptidase $\mathrm{B}$ almost abolished proenzyme activation by tPA.

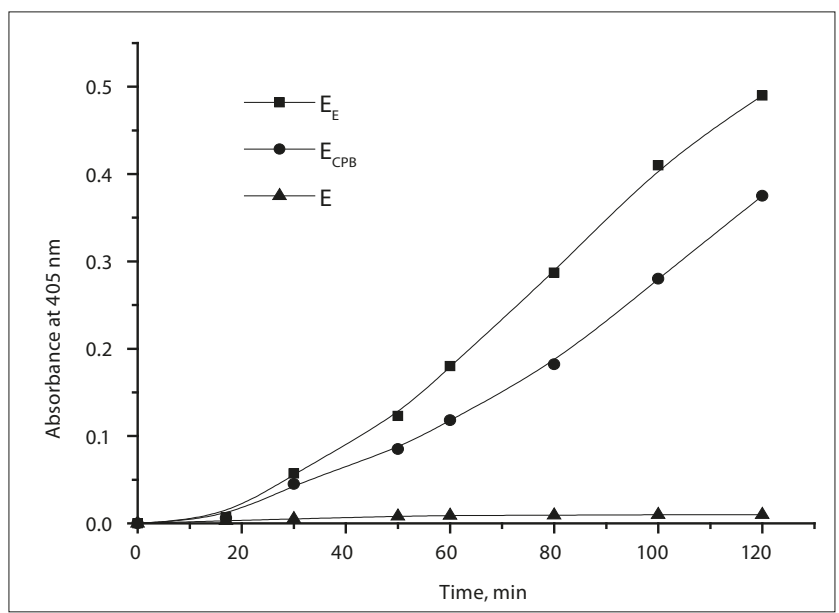

Figure 7. Potentiation of $t P A$-catalysed plasminogen activation by fragment $E$. Plasmin generation in the presence of early, late and carboxypeptidase B treated fragment $E$ (molar ratio fragment/plasminogen was $1 / 1$ ) measured by cromogenic substrate assay

The effect of fibrinogen fragments on plasmin fibrinolytic activity was studied using the turbidimetric method. Fragments were taken in equimolar quantities to plasmin $(20 \mu \mathrm{M})$. Fragments $\mathrm{D}$ and $\mathrm{E}$ did not change the process of polymeric fibrin lysis by plasmin. The rate of clot lysis reaction $\mathrm{V}$ without effectors was $0.2 \pm 0.02$, whereas in the fragments $\mathrm{E}$ and $\mathrm{D}$ presence it was $0.215 \pm 0.025$ and $0.210 \pm 0.02$, respectively. Increasing of each fragment concentration up to 40 -fold excess did not affect the fibrinolytic activity of plasmin.

The addition of blood plasma as a a2-antiplasmin source into the reaction mixture of polymeric desAB-fibrin and plasmin resulted in total inhibition of fibrinolysis ( $0 \%$ lysis versus $100 \%$ without plasma addition). Plasmin preincubation with equimolar amounts of fibrinogen fragments $\mathrm{E}$ and $\mathrm{D}$ did not affect fibrinolysis suppression by a 2 -antiplasmin. Fibrin clot formed but its lysis was not observed. Even 20-fold molar excess of fragments did not change the inhibitor activity.

\section{DISCUSSION}

The fibrinogen molecule contains specific plasminogenand tPA-binding sites which are hidden in the native state but exposed under fibrin polymerisation. During the fibrinogenolysis, plasmin cleaves fibrinogen into fragments $\mathrm{E}$ and D. Fragment D is known to have a plasminogen-binding site in the Aa148-160 region, and the tPA-binding site in the $\gamma 312-324$ region [12]. However, the effect of fragment D on plasminogen activation by tPA, with and without fibrin, was not observed (Fig. 1, 2). The absence of the effect suggests that the fragment D molecule does not comprise the exposed sites for plasminogen activation. This data is consistent with the concept of fibrinolysis initiation: that exposition of plasminogen- and tPA-binding sites in D-domain with subsequent plasmin generation require conformational changes occurring upon polymerization [1].

It was shown that fragment E can bind Glu- and Lysplasminogen with the same affinity in 2 binding regions. Isolated plasminogen fragments K1-3 and mini-plasminogen also specifically bind to this fragment $[13,14]$. The presented data demonstrates that early plasmic degradation product fragment $\mathrm{E}_{\mathrm{E}}$ can stimulate plasmin generation by tissuetype activator, while late fragment $\mathrm{E}_{\mathrm{L}}$ does not potentiate this process (Fig.2). Maximum potentiation effect at molar ratio plasminogen to $\mathrm{E}_{\mathrm{E}} 4 / 1$ suggests that 4 molecules is the maximum amount of plasminogen bound to $\mathrm{E}_{\mathrm{E}}$ (Fig. 3).

Fragment $\mathrm{E}_{\mathrm{L}}$, unable to stimulate plasminogen activation, differs from $\mathrm{E}_{\mathrm{E}}$ in the lack of $24 \mathrm{~N}$-terminal amino acids in the A $\alpha$-chain and C-terminal B $\beta 121$ (122) amino acids (Fig. 8). It is probable that the presence of these amino acids in $\mathrm{E}_{\mathrm{E}}$ causes its potentiation effect, and is essential for plasminogen and tPA binding.

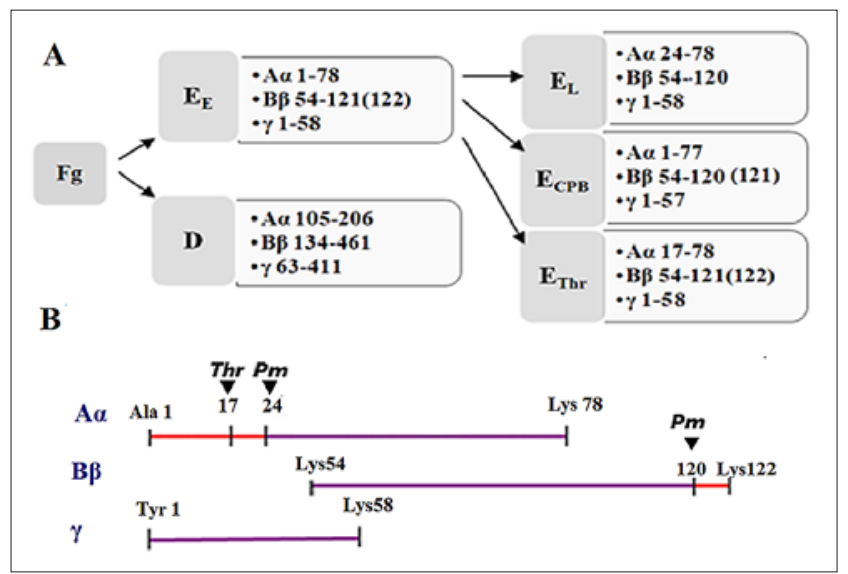

Figure 8. Structure of fibrinogen degradation products

A. Polypeptide chains composition of fragments. Early and late fragments $D$ are the same. Early $E_{E}$ and late $E_{t}$ fragments and fragments treated by carboxypeptidase $B\left(E_{C P B}\right)$ and thrombine $\left(E_{T h r}\right)$ have different carboxy- and aminoterminus of $A a$ and $B \beta$ chains.

B. Points of plasmin and thrombin action in fragment $E_{E}[15,16]$. Carboxypeptidase $\mathrm{B}$ cleaves binds only in front of C-terminal lysines.

tPA binds to partially digested fibrin and FDPs via their C-terminal lysines by lysine-binding site of kringle 2 [17]. Probably, a similar mechanism is presented in the binding to fibrinogen fragments. The same pattern of tPA binding to $\mathrm{E}_{\mathrm{E}}$ and $\mathrm{E}_{\mathrm{t}}$ fragments indicates that the $24 \mathrm{~N}$-terminal amino acids of the Aa-chain is unnecessary for the interaction with activator. This is supported by the data about tPA-binding ability of fibrin fragments $E_{1}$ and $E_{3}$, which is similar to $E_{E}$ and $E_{L}$, respectively [18]. On the other hand, the presence of $\mathrm{C}$-terminal lysines is urgent for tPA binding to fragment $\mathrm{E}$. This is confirmed by the reduction of the activator binding in $\varepsilon$-ACA presence (Fig. 5).

Fragment E interaction with Glu-plasminogen depends on C-terminal lysines and N-terminal Aa1-17 (Fig. 6, 7). Its C-terminal lysines are important but not crucial for this process. Carboxypeptidase B treatment only partially declined its level, although without lysine residues Aa78, $\mathrm{B} \beta 121-122$ and $\gamma 58 \mathrm{E}_{\mathrm{E}}$ completely lose their potentiating effect on plasminogen activation by tPA.

C-terminal lysines of all 3 chains pair and 16 or 23 $\mathrm{N}$-terminal residues of $\mathrm{A} \alpha$-chain are necessary for fragment $\mathrm{E}$ 
stimulating action on plasmin generation. Structure analysis of $\mathrm{E}_{\mathrm{E}}, \mathrm{E}_{\mathrm{L}}, \mathrm{E}_{\mathrm{CPB}}$ and $\mathrm{E}_{\mathrm{Thr}}$ and obtained data allow assuming the interaction between $\mathrm{C}$-terminal lysine of $\mathrm{A} \alpha$ - and $\gamma$-chains and lysine-binding site of tPA kringle 2 . The presence of thrombin-activable fibrinolysis inhibitor in circulation can attenuate fragment E-mediated plasminogen activation by removing of $\mathrm{C}$-terminal lysines, and in this way reduce the affinity of $\mathrm{E}$ for tissue-type plasminogen activator [18].

The lack of Aa1-16 and B $\beta 120-122$ demolishes the 2-sites binding of the plasminogen molecule. Thus, complete plasmic digestion of fibrinogen fragment E results in the total reduction of the potentiating ability. Therefore, the remaining plasminogen and $\mathrm{tPA}$ binding ability of $\mathrm{E}_{\mathrm{L}}$ can decrease fibrinolytic activation rate by the complex formation with proenzyme and its activator without enzyme generation.

Fibrinogen fragments D and E, compared to fibrin, have lower affinity to plasmin and do not attenuate the clot lysis. Excessive amounts of plasmin which get into bloodstream are fast inhibited by a2-antiplasmin [19]. Plasmin bound to fibrinogen fragments is susceptible to inhibition by a2antiplasmin. Under the normal level of the plasmin inhibitor, the fragments-associated enzyme is neutralized. In other cases, this may result in non-specific proteolysis and further bleeding.

\section{CONCLUSIONS}

The results of the presented study demonstrate that fibrinogen degradation products can affect the fibrinolytic process in several ways. Early product fragment $\mathrm{E}_{\mathrm{E}}$ binds to plasminogen and tissue-type plasminogen activator, and enhances plasminogen conversion into plasmin. For this process, all C-terminal lysine residus of 3 chains pair and 16 or $23 \mathrm{~N}$-terminal amino acid residues of $\mathrm{A} \alpha$-chain are essential. C-terminal lysines of fragment $\mathrm{E} A \alpha$ - and $\gamma$-chains and lysine-binding site of tPA kringle 2 are responsible for the interaction between these proteins. Binding of fragment E to plasminogen is provided by the N-terminal Aa1-19 and C-terminal B $\beta 120-122$ regions. Late plasmic fibrinogen degradation product fragment $\mathrm{E}_{\mathrm{L}}$ loses the ability to potentiate plasmin generation, but can bind proenzyme and its activator. Fragment D has no binding abilities towards plasminogen and tPA. None of fibrinogen fragments protected plasmin from a2-antiplasmin inhibition. It is concluded that at over-activation of the fibrinolytic system and subsequent fibrinogenolysis, the products of fibrinogen degradation can bind plasminogen and tPA and potentiate the generation of plasmin, which will be inhibited under the normal level of the plasmin inhibitor.

\section{REFERENCES}

1. Yakovlev S, Makogonenko E, Kurochkina N, et al. Conversion of fibrinogen to fibrin: mechanism of exposure of tPA- and plasminogenbinding sites. Biochemistry 2000; 39: 15730-15741.

2. Cesarman-Maus G, Hajjar KA. Molecular mechanisms of fibrinolysis. Br J Haematol. 2005; 129(3): 307-321.

3. Levi M, Shcultz M, van der Poll T. Coagulation biomarkers in critically ill patients. Crit Care Clin. 2011; 27(2): 281-297.

4. Rodgers G M. Acquired coagulation disorders. In: Arber AD, Glader B, at al. Wintrobe's Clinical Hematology. Twelve ed. Lippincott Williams \& Wilkins; 2013: 1187-1217.

5. Hasan AK, Chang WS, Budzynsky A. Binding of Fibrin Fragments to One-Chain and Two-Chain Tissue-Type Plasminogen Activator. Blood. 1992; 79(9): 2313-2321.

6. Weitz JL, Leslie B, Ginsberg J. Soluble Fibrin Degradation Products Potentiate Tissue Plasminogen Activator-induced Fibrinogen Proteolysis. J Clin Invest. 1991; 87: 1082-1090.

7. Varetska TV. Microgeterogenety of fibrinogen. Cryofibrinogen. Ukr Biochem Zhurn. 1960; 32: 13-24.

8. Deutsch DG, Mertz ET. Plasminogen purification from human plasma by affinity chromatography. Science 1970; 170: 1095-1096.

9. Belitser VA, Platonova TN, Musyalkovskaya AA. Inhibition of fibrinmonomer polymerization by products of fibrinolysis - the fragments D and D-D. DAN SSSR 1986; 291: 1001-1004.

10. Pozdnjakova TM, Musjalkovskaja AA, Ugarova TP, Protvin DO, Kotsjuruba VN. On the properties of fibrin monomer prepared from fibrin clot with acetic acid. Thromb Res. 1979; 16: 283-288.

11. Bouvier SA, Beretta-Piccoli M, Giacometti N. Light scattering measurements of polimerization and depolimerization of fibrin: a tool for studing coagulation and fibrinolysis. Progress in chemical fibrinolysis and thrombolysis. N.Y.: Raven Press; 1975; 1: 281-288.

12. Nieuwenhuizen W. Fibrin-mediated plasminogen activation. Ann N Y Acad Sci. 2001; 936: 237-246.

13. Kudinov SA, Andrianov SI, Lezhen TI. Binding of lys-plasminogen to E-fragment of fibrinogen. Biokhimiia1988; 53(10): 1684-1690.

14. Grinenko TV, Tret'iachenko VG, Skomorovskaia EV, Kudinov SA. Binding of Glu-plasminogen by fibrinogen and byproducts of its proteolysis. 1989; 54(2): 213-220.

15. Collen D, Kudryk B, Hessel B, Blomback B. Primary structure of human fibrinogen and fibrin. Isolation and partial characterization of chains of fragment D J Biol Chem. 1975; 250(15): 5808-5817.

16. Garlund B. Human fibrinogen amino acid sequence of fragment E and adjacent structures in the $A \alpha$ - and $B \beta$-chain. Thromb Res. 1977; 10(5): 689-702.

17. Bakker AH, Weening-Verhoeff EJ, Verheijen JH. The role of the lysyl binding site of tissue-type plasminogen activator in the interaction with a forming fibrin clot. J Biol Chem. 1995; 270(21): 12355-12360.

18. Stewart RJ, Fredenburgh JC, Rischke JA, Bajzar L, Weitz JI. Thrombinactivable fibrinolysis inhibitor attenuates (DD)E-mediated stimulation of plasminogen activation by reducing the affinity of (DD)E for tissue plasminogen activator. A potential mechanism for enhancing the fibrin specificity of tissue plasminogen activator. J Biol Chem. 2000; 275(47): 36612-36620.

19. Paul B. Coughlin. Antiplasmin. The forgotten serpin? FEBS Journal. 2005; 272: 4852-4857. 